\title{
Public Perceptions of NATO: US Leadership and Defense Spending
}

\author{
Erik M. Fay \\ University of Kentucky \\ $9 / 15 / 20$
}

\begin{abstract}
This study examines the factors that influence public opinion on the topic of international security and foreign policy preferences in 13 NATO member countries between 2004-2012. Specifically, I focus on how individual foreign policy preferences (i.e. support for strong U.S leadership) drive public perceptions of NATO as being essential for security. I then explore if there is divergence within NATO in the form of differences in public opinion due the level of military spending within each country. These questions fill an important gap in the literature by tying individual level public opinion to questions of burden sharing and free riding within NATO, with the goal of explaining how citizens' preferences are influenced by their domestic environment. Empirical evidence from a multilevel model suggest that individuals who prefer strong US leadership are more likely to perceive NATO as essential for security unless they are in a country that met the $2 \%$ defense spending criteria established by the alliance.
\end{abstract}




\section{Introduction}

Maintaining security against all present and potential external threats is a critical issue that requires countries to continuously maintain a balance between domestic and foreign policy. While the most reliable way for a country to increase its security is through the use of domestic policies such as increasing military spending, this approach can be extremely costly and unpopular in the eyes of the public (Bove, Efthyvoulou, and Navas 2017). Alternatively, countries can increase security cheaply with foreign policy tools like the creation of a military alliance such as the North Atlantic Treaty Organization. Foreign policy tools such as NATO can enhance security without using costly domestic policy, yet it is only as effective as each member's commitment to the collective defense of the alliance (Blum and Potrafke 2019). While historically NATO has maintained the appearance of a unified alliance, questions of the continued sustainability of NATO have been discussed publicly by elites and have drawn the attention of the public at large due to the direct security implications regarding the members continued commitment to the collective defense of the alliance (Fay 2020). This study will seeks to explain how individual level foreign policy preferences and contextual factors such as levels of military spending drive public perceptions of NATO as being essential for security.

Due to NATO Members being democracies, leaders must contend with preferences of the mass public when crafting national policies. Elites respond to the preferences of their constituents due to the electoral incentives associated with democratic systems and their desire to gain and maintain political power (Soroka and Wlezien 2010). As such, any shift in public opinion should create incentives for leaders to adjust their policy preferences and behavior to align with the position of 
their supporters. While electoral incentives are most commonly associated with domestic policies, they can also motivate the foreign policy decisions of the elite (Whitten and Willaims 2011). While this implication suggests that public opinion can play an important role in elite behavior, less is known about what drives these shifts in public opinion. I seek to explain the current tensions within the alliance by leveraging public opinion to answer the question: What determines whether an individual will perceive NATO as being essential for security?

By focusing on the role of that individual foreign policy preferences play in altering the public perceptions of NATO being essential for security, I present a theoretical argument that can be used to generate a policy solution designed to ensure continued stability and strengthen security. I argue that individuals who prefer strong US leadership in world affairs will be more likely to perceive NATO as being essential for security. The logic of this follows that wanting strong leadership from a powerful external entity such as the US, is motivated by security concerns within the international system. However, this alone fails to explain the current division within the alliance that is due to the unequal burden sharing that is taking place, where some alliance members are under-contributing to the overall security of the alliance. I further argue that the relationship between preferring strong US leadership and perceptions of NATO is conditional based on if the individual is in a country who fulfills their commitment to spend 2\% of their GDP on defense, with the effect of meeting the $2 \%$ spending threshold reducing the influence that preferring US leadership has on support for NATO. As this topic has been heavily focused in the media, individuals will not want their government to continue to 
contribute to international institutions if other members are under-contributing and as such would rather forgo the benefits of NATO due to increased resentment from being taken advantage of by free riders.

To empirically test this theory, I leverage a cross-national large $\mathrm{N}$ public opinion dataset from the Transatlantic Trends Series (TTS) that is conducted annually by the German Marshall Fund (Everts et al 2012). The TTS surveys aim to address issues related to foreign policy preferences and includes over 20,000 individual respondents from a total of 13 NATO countries from 2008 to 2012, making it ideal for this study. As my goal is to identify what determines whether an individual will perceive NATO as being essential for security, I utilized a multilevel logistic regression with a cross level interaction to analyze the effect that meeting the $2 \%$ defense spending agreement has on the relationship between perceptions of US leadership and perceptions of NATO. I find support for my theory, which suggests that support for international institutions such as NATO is influenced by individual foreign policy preferences as well as contextual factor such as levels of defense spending.

This finding has direct policy implications due to the electoral incentives that are created when shifts in public opinion occur. If individuals believe that they are being taken advantage of by free riders in NATO, they will be less likely to support the alliance due to resentment, which in turn will create an incentive for elites to adopt policies that are less supportive of the alliance. In recent years this issue of resentment has become more of a concern due to the high level of media attention the alliance has received. This theoretical argument provides a framework that can 
explain the current tension within the alliance, but more importantly allows for the identification of potential policy solution that might ensure future stability within the alliance.

\section{Public Perceptions of NATO: US Leadership and Defense Spending}

While defense spending is crucial in order to maintain an adequate level of security within the international system, this spending comes with a costly tradeoff. Increasing defense spending shifts resources away from domestic programs which can be used by elites to provide their constituents goods in order to be reelected (Sandler and Shimizu 2012). In an ideal world, states would prefer to allocate all their resources domestically, but due to the anarchic nature of the international system, they must ensure their security through military spending or a foreign policy tool such as a military alliance (Collier and Hoeffer 2002). How states allocate their resources can be tied to how secure they feel within the international system, which can be viewed as a function of potential external threats and the believe that the members of their alliance will fulfill their commitment in the event of conflict. While many scholars have researched the factors that lead citizens to support increased military spending (Carter and Fay 2019; Eichenberg and Stoll 2017;), less is known about what determines whether an individual will support a military alliance. I seek to address this gap by presenting a theory that combines domestic and international politics with an individual level explanation that can explain the current tensions facing the North Atlantic Treaty Organization.

I focus first on explaining the role that an individual's foreign policy preferences have on in altering the perception of NATO being essential for their 
security. Specifically, I present an argument that explains what would lead individuals to prefer strong US leadership in the international system. By examining individual preferences on strong US leadership in relation to their perception that NATO is essential for security, a direct connection between preferences and security can be made. NATO has remained a key component of the US foreign policy agenda within the international system since its creation (Spangler 2017). This relationship has allowed the United States to embrace the role of a leader in geopolitics due to the influence it has gained from within NATO where they provide the alliance with the bulk of its security (Simon and Lovrich 2010). Many individuals view the United States as the unofficial leader of NATO based off its status as the lone hegemon and the massive amount of power they have gained through high levels of defense spending (Ringsmose 2010). Individual motivations for preferring strong US leadership can be derived from the existence of security concerns within the international system, which strong leadership from a powerful external entity such as the US can deter without the need for increased defense spending from alliance members. As such, I argue that individuals who prefer strong US leadership will be more likely to perceive NATO as being essential for security.

H1: Individuals that prefer strong US leadership will be more likely to perceive NATO as being essential for security.

While relying on an alliance for your security is cheap, it is also risky. This risk means NATO leaders must balance the domestic and foreign policy preferences 
of their constituents while maintaining adequate levels of security via a combination of domestic defense spending and foreign policy tools such as military alliances. Because many citizens view security as an abstract concept that has no tangible benefits, individuals tend to prefer policies that emphasis spending on domestic programs that directly benefit themselves instead of enhancing security via increased defense spending (Powell 1993). While electoral incentives such as this are typically thought of as drivers of domestic policy, they can shape foreign policy both directly and indirectly as well. The direct influence of public opinion in response to favorable or unfavorable policy positions can result in leaders altering their behavior to meet the demands of their constituency (Wlezien 1995). If public opinion shifts to viewing NATO as not essential for security, elites will adopt a similar position or they will be replaced by someone who will.

In the context of NATO, public opinion can indirect influence foreign policy due to the incentive an alliance leader has to become a free ride in order to provide their constituents with more of the domestic polices they prefer at the cost of increased security in order to get reelected, while still maintaining security due the collective defense benefits the alliance provides (Soroka and Wlezien 2010). This can result in increased public support for the alliance domestically due to the peace dividends that were gained, but this behavior can also cause a shift against the alliance in non-free riding states due to building resentment, resulting in a loss of support that can undermine the credibility of collective security if members are perceived as unreliable. As such, I argue that individuals who are in countries that meet the $2 \%$ spending threshold will be less likely to perceive NATO as being 
essential for security due to less reliance on the alliance and concerns of free-riding behavior.

H2: Individuals that are in a country that meets the $2 \%$ spending requirement will be less likely to perceive NATO as being essential for security.

It is possible that there is an interaction effect taking place, where foreign policy preferences have a conditional effect on the perception of NATO based on contextual factors such as level of military spending. In other words, the relationship between individual preferences and perception of NATO may be stronger in countries with either low levels of military spending. Countries that have lower military spending may be free riding, and thus individuals within these countries will be more likely to view NATO as essential for security. Alternatively, individuals in countries that have high military spending may be less supportive of NATO due to the belief that other members may be free riding off their higher levels of military spending without contributing the to the overall security burden.

Specifically, I expect that citizens who prefer strong US leadership will be more likely to perceive NATO as being essential for security, but only if they are in a country that is not meeting the $2 \%$ military spending agreement that NATO set during the Warsaw Summit (NATO 2014). Due to the high level of media attention the alliance has received regarding military spending, it is widely known which alliance members are free riding. While there is an incentive for citizens to support free-riding behavior (view NATO as essential but not meeting the $2 \%$ agreement) 
due to the potential "peace dividends" gains, this behavior can undermine the stability of the alliance and can induce huge costs in the event of conflict (Olson 1965, Olson and Zeckhauser 1966). I argue that individuals that prefer strong US leadership will perceive NATO as essential due to the US being viewed as the unofficial leader of the alliance and providing the bulk of security benefits for NATO members. Individuals in countries that do not meet the $2 \%$ spending requirement and prefer strong US leadership will be the most likely to view NATO as essential, as they are free riding off the power the US provides. Yet, if you are in a country that is fulfilling its commitment and spending $2 \%$, you will be less likely to view NATO as essential due to resentment of being taken advantage of by free riding members. More importantly, even if you prefer strong US leadership, but are in a country that is spending $2 \%$, you will not view NATO as essential for security. I argue that his is due to concerns of free riders taking advantage of the alliance, but more importantly due to concerns regarding the members commitment to collective security. Which leads to my final hypothesis:

H3: Individuals that prefer strong US leadership will be more likely to perceive NATO as being essential for security unless they are in a country that meets the $2 \%$ spending requirement.

\section{DATA AND METHODS}

Research utilizing public opinion data to examine foreign policy preferences has largely focused on individuals in the United States due to the lack of 
representative cross-national surveys. However, this limitation is starting to be overcome due to a new focus on collecting cross-national data. The Transatlantic Trends Series dataset (TSS), which was funded by the German Marshall Fund (Everts et al 2012), is one such attempt at collecting individual level data on foreign policy preference in a cross national manner. The TSS survey covers a total of 13 NATO countries and is nationally representative, which allows researchers to conduct cross-national empirical analysis of public opinion data in order to examine theories regarding foreign policy preferences at the individual level. This data contains 3 survey waves $(2008,2011$, and 2012) with each country-year having 1000 respondents.

Dependent Variables: NATO as Essential

To construct my dependent variable, I use a survey question, which can be seen below. This will be used to gauge the perception of NATO being essential for their security. This question will be converted to a dichotomous measure that will take the value of 1 if the respondent indicates that NATO is essential for security and 0 if no longer essential.

Some people say that NATO is still essential to our country's security. Others say it is no longer essential. Which of these views is closer to your own?

1. Still Essential

2. No Longer Essential

\section{Individual Level Independent Variables}

The primary variable of interest in explaining the dependent variable, viewing NATO as essential for security, is based off a survey question that ask the 
respondent their opinion regarding their desire for the US to exert strong leadership in world affairs. To construct this variable, I follow the same coding scheme as used for the creation of my dependent variable, with the measure taking a value of 1 if the respondent says it is either very desirable or somewhat desirable that the US should exert strong leadership in world and 0 if they say undesirable or Very undesirable. The original survey questions that were used can be seen below.

How desirable is it that the USA exerts strong leadership in world affairs?

1. Very desirable

2. Somewhat desirable

3. Somewhat undesirable

4. Very undesirable

\section{Contextual Level Independent Variables}

In order to examine how the $2 \%$ spending threshold influences individual level preferences, it is important to include a country level variable to account for cross-national variation. This contextual level variable will identify if a country spends at least 2 percent of their overall GDP on military as state by NATO (World Bank 2010). The inclusion of this variable is crucial as the level of military spending should influence if an individual will be likely to view NATO as essential, but more importantly, will allow for a cross level interaction with the primary independent variable. For instance, this approach can identify if there is a statistical difference between countries that are above or below the $2 \%$ threshold and if this difference alters the relationship between preferring US leadership and perceptions of NATO. Control Variables 
The literature on foreign policy preferences has identified several variables that can influence public opinion such as if an individual views NATO as essential for security. The control variables included in this analysis are meant to identify if any individual level factors will influence the foreign policy preferences of an individual. The first set of variables is meant to capture individual level characteristics and include: Left-Right ideology (Peffley and Hurwitz 1992), gender (Eichenberg and Stoll 2012), age (Ellis and Faricy 2011), and occupation (Kertzer and Zeitzoff 2017).. The second set of variables is meant to capture a respondents existing policy preferences and includes: if the respondent is a hawk/dove (Asmus, Everts, and Isernia 2004), if they favor increased military spending (Fay 2020), if they prefer economic power over military power (Domke, Eichenberg, and Kelleher 1987), if they want an independent foreign policy (Eichenberg and Stoll 2017), and if they prefer EU leadership (Becker and Malesky 2017).

\section{Empirical Strategy}

In order to empirical test the hypotheses discussed above, I utilize a multilevel logistic regression with random effects in order to estimate the individual and contextual level effects (Steenbergen and Jones 2002). The TSS data is organized hierarchically with individual respondents in a NATO country. This nested structure allows for both individual level and contextual characteristics to influence the public perception of NATO being essential for security. By individual level factors with country level characteristics I am able to estimate the direct effects of variables at both levels. Additionally, this approach allows for the inclusion of a cross level interaction in order to see if citizen's views of NATO are conditioned 
by the level of military spending of the country they are in. This will present an opportunity to examine if individual foreign policy preferences are conditioned by domestic politics (Paxton and Knack 2008).

\section{Results}

Before examining the potential cross level, relationships discussed above, I will estimate a baseline model that is not multilevel. By pooling all of the NATO members into one model and including only individual level variables I will be able to identify a baseline to test the viability of theoretical framework discussed above. A standard logistic regression model was estimated, and the results can be seen in the appendix. The primary individual level variables "US Leadership" is positive and statistically significant, suggesting that individuals that want an external actor to lead are more likely to view NATO as essential for their security as the hypothesis predicted. While this model is underspecified due to only including individual factors, the results are promising. 


\begin{tabular}{lc}
\hline & DV: Perception of NATO \\
\hline (Intercept) & -0.05 \\
& $(0.14)$ \\
Unemployment & $-0.02^{* *}$ \\
& $(0.01)$ \\
Increased Defense Spending & $0.25^{* * *}$ \\
& $(0.04)$ \\
Economic Power & 0.03 \\
& $(0.04)$ \\
Isolationist & $-0.55^{* * *}$ \\
& $(0.03)$ \\
Met 2\% Spending & -0.06 \\
US Leadership & $(0.10)$ \\
EU Leadership & $0.48^{* * *}$ \\
External Threat & $(0.04)$ \\
Hawk & $0.43^{* * *}$ \\
Ideology (Left-Right) & $(0.03)$ \\
Female & $0.11^{* * *}$ \\
Num. obs. & $(0.02)$ \\
Age & $0.30^{* * *}$ \\
Managerial Occupation & $(0.03)$ \\
& $0.14^{* * *}$ \\
US Leadership:Met 2\% & $(0.02)$ \\
& $0.11^{* * *}$ \\
& $(0.03)$ \\
& $0.02^{* * *}$ \\
& $(0.01)$ \\
& $-0.09^{* *}$ \\
AIC & $(0.04)$ \\
& $-0.19^{* * *}$ \\
& $(0.06)$ \\
\hline & 36195.10 \\
& 36344.71 \\
& -18079.55 \\
& 30074 \\
& 49 \\
\hline
\end{tabular}

${ }^{\cdots} p<0.01,{ }^{*} p<0.05,{ }^{\circ} p<0.1$ 
The fully specified model which includes all of the contextual level variables along side a coefficient plot presenting odds-ratios can be seen above in table 1 , while the effect of the cross level interaction can be seen in figure 1 . This model includes random intercepts and random slopes that will allow for a better understanding if the relationship between individual perception of NATO and support for US varies based on a respondents country. The level 2 variable that measures if a member met the $2 \%$ spending agreement does not achieve statistical significance on its own, but the inclusion of a cross level interaction allows for hypothesis 1 to be tested by allowing for the level of military spending in a country to condition the effect of US leadership on the perception of NATO being essential for security.

Figure 1: Cross-Level Interaction

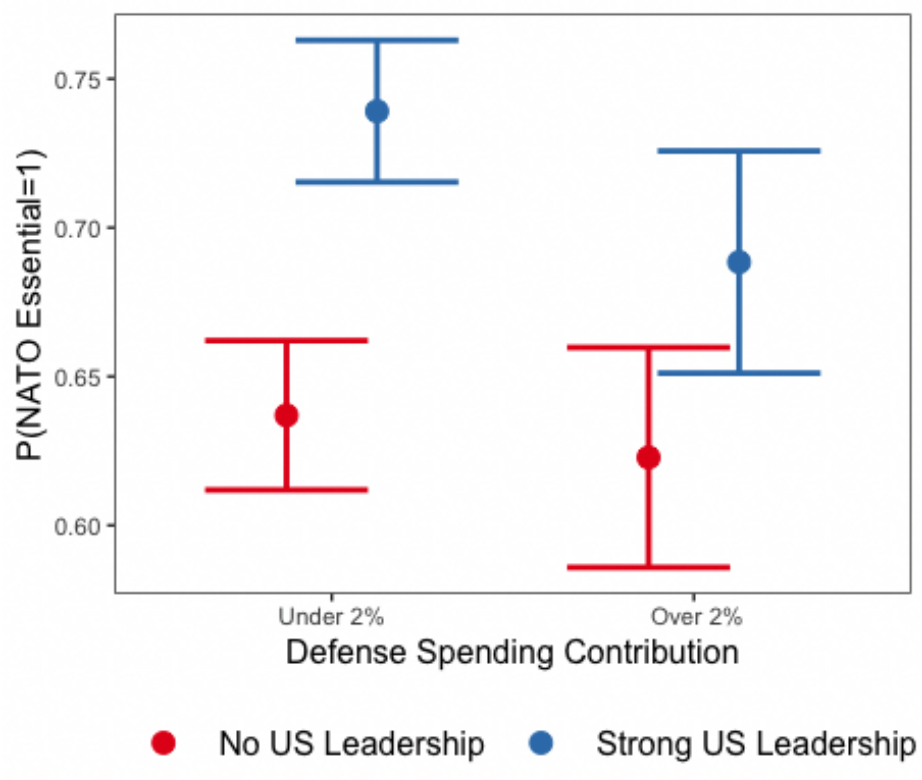


Support for US leadership has a positive and statistically significant effect on the perception of NATO, but the interactive term is negative and statistically significant, which suggest that individuals who want US leadership in countries with low levels of military spending are more likely to perceive NATO as being essential for security compared to individuals in countries with high levels of spending as the hypothesis predicted. For a better understanding of the interactive effect between support for US leadership and meeting the $2 \%$ spending requirement, the predicted probabilities for viewing NATO as essential for security based on support for US leadership and meeting the spending requirement can be seen in figure 2 above.

\section{CONCLUSION}

In this paper, I examine what determines whether an individual will perceive NATO as being essential for security. I argued that both domestic and foreign policy preferences influence public opinion regarding the continued need and role of NATO in providing security for its members. Data from the Transatlantic Trends Survey is utilized to empirically test my proposed hypothesis using a multilevel model that include cross level interactions, which allowed for the inclusion of contextual factors that can condition the effect of individual level factors. The TSS survey allowed me to combine individuals' preferences regarding foreign policy positions and the perception of NATO in order to provide a test of individual and contextual level theories. The results of the multilevel model show support for hypothesis 1 which suggests that individuals who desire strong leadership from the US will have an increased probability of viewing NATO as essential for security. 
I argue and show that members who are fulfilling their commitment to the collective security of the alliance are growing to resent the free riding members who are spending less on military. This analysis showed that the level of military spending interacts with the foreign policy preferences of individuals that desire strong US. Individuals in states that don't meet the military spending requirement who desire strong US, are more likely to perceive NATO as essential for security than both non-US supporters and supporters in countries that met the agreed upon requirement. This finding confirms the presences of cross level interaction as hypothesis 3 predicted and suggests that individuals shape their foreign policy preferences based on the contextual environment which can in turn be influenced by domestic policy such as defense spending.

This study has several important policy implications due to on-going concerns of sustainability and free riding within the military alliance, as it appears that the public is responding to both domestic and foreign policy decisions made by the elite. This results in a shift in public opinion and provides incentive for leaders to adjust their own policy preferences to align with their constituents due to electoral incentives. If this is indeed the case, then it is crucial to identify what factors are driving individuals to have a negative perception of NATO as there is potential for the public to elect leaders who undermine the collective security of the alliance. If you believe that the public is able to sway policy through the threat of electoral punishment, then the findings presented here present a potential explanation for the free riding behavior within NATO. This public opinion-elite dynamic warrants further attention, as it provides a theoretical explanation that ties 
individual preferences to elite policymakers which in turn can be tied to the current issues threatening the sustainability of NATO. 


\section{References}

Collier, P., and Hoeffler, A. (2002). Military Expenditure: Threats, Aid, and Arms Races. Policy Research Working Papers.

Domke, W., Eichenberg, R., and Kelleher, C. (1987). Consensus Lost?: Domestic Politics and the "Crisis" in NATO. World Politics,39(3), 382-407.

Eichenberg, R., and Stoll, R. (2012). Gender Difference or Parallel Publics? The Dynamics of Defense Spending Opinions in the United States, 1965-2007. Journal of Conflict Resolution, 56(2), 331-348.

Eichenberg, R., and Stoll, R. (2017). The Acceptability of War and Support for Defense Spending. Journal of Conflict Resolution, 61(4), 788-813.

Ellis, and Faricy. (2011.). Social Policy and Public Opinion: How the Ideological Direction of Spending Influences Public Mood. The Journal of Politics, 73(4), 1095-1110.

Everts, P, Kennedy, , Pierangelo, Zsolt, and Eichenberg, Transatlantic Trends Survey, 2012. Ann Arbor, MI: Inter-university Consortium for Political and Social Research

Kertzer, J., and Zeitzoff, T. (2017). A Bottom-Up Theory of Public Opinion about Foreign Policy. American Journal of Political Science, 61(3), 543-558.

NATO (2014) Wales Summit Declaration

Olson, M (1965) The Logic of Collective Action. Cambridge, MA: Harvard University Press

Olson, M, Zeckhauser, R (1966) An economic theory of alliances. Review of Economics and Statistics 47(Aug.): 266-79

Paxton, P and Knack, S (2008) Individual and Country-Level Factors Affecting Support for Foreign Aid. Policy Research Working Paper. World Bank Development Research Group

Peffley, M., and Hurwitz, J. (1992). International Events and Foreign Policy Beliefs: Public Response to Changing Soviet-U.S. Relations. American Journal of Political Science, $36(2)$

Powell, R. (1993). Guns, Butter, and Anarchy. American Political Science Review, 87(1)

Ringsmose, J. (2010). NATO Burden-Sharing Redux: Continuity and Change after the Cold War. Contemporary Security Policy,31(2), 319-338. 
Sandler, T., and Shimizu, H. (2012). NATO Burden Sharing 1999-2010. Foreign Policy Analysis, 10(1), 43-60.

Simon, C., and Lovrich, N. (2010). Citizen Support for Military Expenditures: A Longitudinal Analysis of U.S. Public Opinion, 1999-2002. Armed Forces and Society., 36(3), 454480 .

Soroka, S., and Wlezien, C. (2010). Degrees of Democracy: Politics, Public Opinion, and Policy. Cambridge University Press

Spangler, E. (2017). Allies with Benefits: US Effect on European Demand for Military Expenditures. Defence and Peace Economics,1-17.

Steenbergen, M., and Jones, B. (2002). Modeling multilevel data structures. American Journal of Political Science, 46(1), 218-237.

Wlezien, Christopher. 1995. -The Public as Thermostat: Dynamics of Preferences for Spending. American Journal of Political Science 39 (4): 981-1000.

World Bank (2011) World Development Indicator databank (http://databank.worldbank.org/ddp/home) 


\section{Appendix}

Pooled Logistic Regression Model

Breakdown of Individuals by Response on DV by US Leadership and Defense Spending

Technical Notes

TSS Survey Questions 
TABLE 2 Pooled Logistic Regression Model

\begin{tabular}{|c|c|}
\hline & DV: Perception of NATO \\
\hline (Intercept) & $\begin{array}{c}-0.28^{* * *} \\
(0.08)\end{array}$ \\
\hline Met $2 \%$ & $\begin{array}{c}-0.11^{* * *} \\
(0.03)\end{array}$ \\
\hline Unemployment & $\begin{array}{c}-0.01^{* *} \\
(0.00)\end{array}$ \\
\hline Increased Defense Spending & $\begin{array}{c}0.29^{* * *} \\
(0.04)\end{array}$ \\
\hline Economic Power & $\begin{array}{l}0.08^{*} \\
(0.04)\end{array}$ \\
\hline Isolationist & $\begin{array}{c}-0.53^{* * *} \\
(0.03)\end{array}$ \\
\hline US Leadership & $\begin{array}{c}0.39^{* * *} \\
(0.03)\end{array}$ \\
\hline EU Leadership & $\begin{array}{c}0.40^{* * *} \\
(0.03)\end{array}$ \\
\hline External Threat & $\begin{array}{c}0.13^{* * *} \\
(0.02)\end{array}$ \\
\hline Hawk & $\begin{array}{c}0.31^{* * *} \\
(0.03)\end{array}$ \\
\hline Ideology (Left-Right) & $\begin{array}{c}0.15^{* * *} \\
(0.02)\end{array}$ \\
\hline Female & $\begin{array}{c}0.10^{* * *} \\
(0.03)\end{array}$ \\
\hline Age Group & $\begin{array}{l}0.02^{* *} \\
(0.01)\end{array}$ \\
\hline Managerial Occupation & $\begin{array}{l}-0.04 \\
(0.04)\end{array}$ \\
\hline AIC & 28863.33 \\
\hline BIC & 28976.33 \\
\hline Log Likelihood & -14417.67 \\
\hline Deviance & 28835.33 \\
\hline Num. obs. & 23645 \\
\hline
\end{tabular}

${ }^{\cdots} p<0.01,{ }^{*} p<0.05,{ }^{*} p<0.1$ 
Breakdown of Individuals by Response on DV by US Leadership and Defense Spending

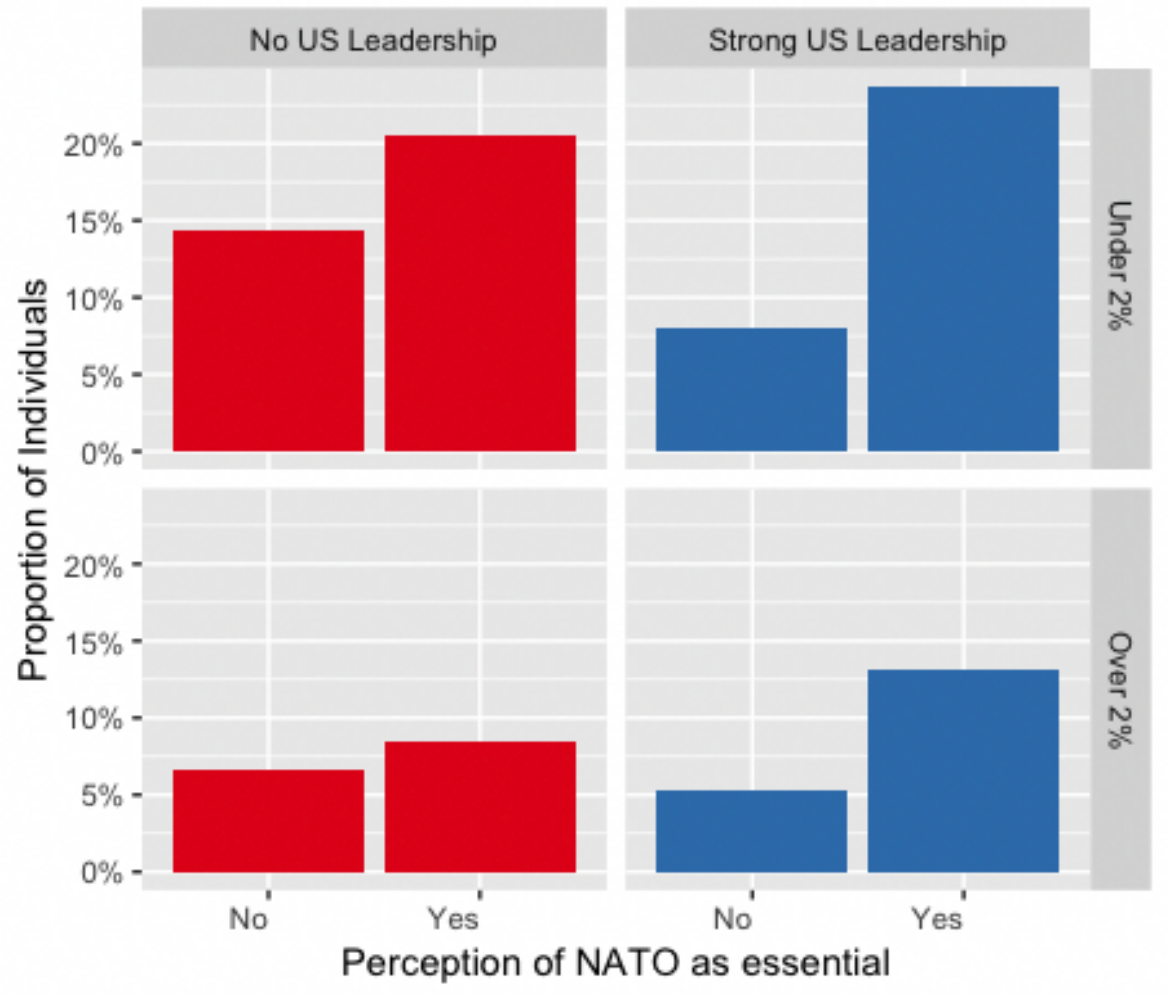




\section{Technical Notes}

Countries included in the sample:

France

Germany

Italy

Netherlands

United Kingdom

Portugal

Spain

Poland

Slovakia

Bulgaria

Romania

Turkey

United States 


\section{Transatlantic Trends Series Survey Questions}

Perception of NATO

Q6. Some people say that NATO is still essential to our country's security. Others say it is no longer essential. Which of these views is closer to your own?

1. Still essential

2. No longer essential

98. Don't Know (SPONTANEOUS)

99. Refusal (SPONTANEOUS)

Support for US Leadership

US Leadership

Q1a. How desirable is it that the USA exerts strong leadership in world affairs?

1. Very desirable

2. Somewhat desirable

3. Somewhat undesirable

4. Very undesirable

5. Neither or both equally (SPONTANEOUS)

98. Don't Know (SPONTANEOUS)

99. Refusal (SPONTANEOUS)

Support for Increased Military Spending

Q25 1. Do you think the [COUNTRY] government should increase, maintain, or decrease spending on the following? - Defense

1. Increase spending

2. Maintain current levels of spending

3. Decrease spending

98. Don't know (SPONTANEOUS)

99. Refusal (SPONTANEOUS)

Gender

D1. Gender

1. Male

2. Female

Left-Center-Right Ideology 
D6. In politics, people sometimes talk of 'left' and 'right'. Where would you place yourself on a scale from 1 to 7 where ' 1 ' means

the extreme left and ' 7 ' means the extreme right? (Europe only)

1. Extreme left

2. Left

3. Center Left

4. Center

5. Center Right

6. Right

7. Extreme Right

8. 98. Don't Know (SPONTANEOUS)

9. 99. Refusal (SPONTANEOUS)

Age

D2. Age respondent (categorical)

1. $18-24$

2. $25-34$

3. $35-44$

4. $45-54$

5. $55-64$

6. $65+$

Hawk

Q34 2. Please tell me to what extent you agree or disagree with each of the following... - Under some conditions, war is necessary to obtain justice

1.Agree Strongly

2. Agree Somewhat

3. Disagree Somewhat

4. Disagree Strongly

98. Don't Know (SPONTAENOUS)

99. Refusal (SPONTAENOUS) 